\section{WORK BEGINS ON BRAND NEW DENTAL HOSPITAL AND SCHOOL}

Work is to start on the first integrated, standalone dental hospital and dental school to be built in the UK for almost 40 years.

Planning permission was granted in December 2012 for the site of the 50 million pound development, which is on the former home of BBC Pebble Mill studios. A four-storey dental hospital and school will be constructed which will house a range

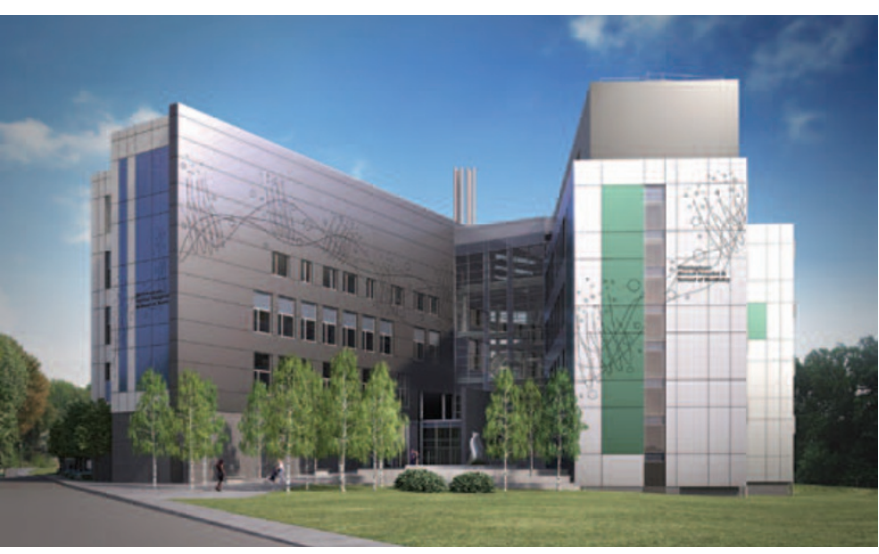

of services for the public including walk-in emergency dental care, restorative, oral surgery, orthodontics and paediatric dentistry. Another wing of the building will provide world-class research facilities and a modern learning environment for more than 600 students and trainees.

Barry Cockcroft, the Chief Dental Officer for England, said: 'The design of the building is innovative and will provide a great opportunity to integrate dental treatment, learning and research in a modern, state-of-theart environment.'

It is anticipated that the new dental hospital and school will open in time for the beginning of the 2015 autumn term.

\section{THOUSANDS MORE STUB IT OUT}

England's NHS stop smoking services helped at least 20,000 smokers kick the habit long term in 2010/11 according to new research published in the British Medical Journal. ${ }^{1}$ The number of smokers who used the service and set a quit date more than tripled from just over 227,000 in $2001 / 02$ to nearly 788,000 in 2010/11. The total number of quitters who had not smoked for four weeks rose from just under 80,000 to almost 270,000 .

1. West R, May S, West M, Croghan E, McEwen A. Performance of English stop smoking services in first 10 years: analysis of service monitoring data. BMJ 2013; 347: f4921.

dealing with prejudice, dentists can finally return to their professional calling...'

Over the past 20 years no dental professional has been linked with the transmission of HIV infection to a patient, and huge advances in anti-retroviral treatment mean that the virus can be suppressed to the point where it is undetectable in a blood test.

HIV-infected healthcare workers may be allowed to undertake certain procedures if they are on effective combination antiretroviral drug therapy (cART), have an undetectable viral load, and are regularly monitored by their treating and occupational health physicians. 